Printed in Great Britain

\title{
MEASUREMENTS OF UNSTEADY PERIODIC FORCES GENERATED BY THE BLOWFLY FLYING IN A WIND TUNNEL
}

\author{
BY RICHARD H. BUCKHOLZ* \\ The Fohns Hopkins University, Baltimore, Maryland
}

(Received 26 March 1980)

\begin{abstract}
SUMMARY
A technique was developed for the measurement of the instantaneous lift and drag forces generated by the blowfly, Sarcophaga bullata, flying fixed in a wind tunnel. Apparatus for the measurement of insect-generated forces was checked in part for mean force accuracy by measurement of the drag on a circular cylinder. Our experimental device detects the sum of the aerodynamic forces and wing inertial forces as experienced by the thorax. The streamwise and vertical force waveforms show a surprising lack of higher harmonic content. Wind speeds in the neighbourhood of the known preferred flying speed were used, without an explicit attempt to nullify the mean vertical and horizontal forces to simulate free flight. Several measurements of the phase angle between the force waveform and the wing beating kinematics indicated that vertical forces in the liftward direction achieved a maximum during the downstroke and thrustward forces achieved a maximum during the upstroke.
\end{abstract}

\section{INTRODUCTION}

The study of insect flight mechanics presents some intriguing problems for experimental and theoretical fluid dynamicists. The present study is an experimental investigation of unsteady lift and drag forces generated by the blowfly, Sarcophaga bullata, 'flying', fixed, in a wind tunnel. We shall be concerned specifically with the frequency, amplitude and phase content of insect-generated force components. Unlike the steady-state aerodynamic experiments, the unsteady, large-amplitude wing motion of the blowfly is difficult for a mechanical wind-tunnel model to emulate. The live-animal experiments as an alternative to mechanical models have been hampered by the lack of special technology for the measurement of the tiny, frequencydependent, forces wrought by insect flapping flight. Yet the unsteady features of insect flight and a technique for measurement of unsteady forces would provide valuable insight into the dynamic features of flapping flight. A principal novelty of the present study is in the development and application of a suitably sensitive force balance.

- Present address: Department of Engineering Science, Division of Engineering and Applied Science, fornia Institute of Technology, Pasadena, California 9125. 
Much of our present knowledge and understanding derive from the measuremene of average forces and, by inference, from kinematic data; the latter, no matter how complete, are by themselves insufficient to describe the associated dynamics. The great difficulty of analysing unsteady finite wing motion has been avoided in some instances by applying steady-state aerodynamics to measured kinematical data (e.g. Jensen, 1956). It is of interest that the average forces estimated by Jensen's quasi-steady analysis compared well with the average force measurements on the locust. However, there are many instances where theoretical estimates indicate that quasi-steady approximations are not suitable. Consequently our approach has been to go beyond the mean force measurements of Weis-Fogh (1956) and Vogel (1966).

For simplicity, an insect with a single pair of functional wings, the blowfly (Sarcophaga bullata), was used as the experimental animal. Furthermore the wing motion of the fly Pharmia regina has been photographed by Nachtigall (1966). The nominal mass of the blowfly is $50 \mathrm{mg}$, which places it between the locust and fruit fly in weight. Some difficulties cannot be avoided, at least at first glance. It is likely that genuine unsteady aerodynamic effects are important because the nominal reduced frequency* based on the wing span is 0.5 and based on the chord it is 0.25 . The nominal Reynolds numbert is 600 , and is far above the small Reynolds number range, yet well below the large Reynolds number studied by engineers.

The experiments give the amplitude, phase and frequency of the force exerted by the thorax of the blowfly. The novel force-measuring device is described elsewhere (Buckholz, 1978, 1979). A parametric aerodynamic performance investigation is beyond the scope of this work although such studies are important problems for future research. The difficulties of testing live insects are aggravated by individual variation of important parameters. General discussions of the problems of insect flight are given by Nachtigall (1974), Wu (1975), and Rainey (1976).

\section{EXPERIMENTAL TECHNIQUE}

The force-measuring technique (Buckholz, 1978,1979 ) is outlined below. The novel force-measuring device was a taut wire transverse to the wind-tunnel air flow, having fixed ends with a live insect tethered near the midpoint. Periodic forces on the wire occurred during flapping flight and produced very small but detectable wire displacements. These displacements were much smaller than either the wing span or chord. The wire was essentially a two-component linear oscillator. In practice, the streamwise and vertical wing displacements were optically detected simultaneously at separate points as shown in Fig. $\mathrm{I}$. The wire sections at the points of displacement detection cut a chord across a laser beam, which had a radial intensity gradient. As the wire section moved within the laser radiation, different amounts of light were reflected, depending upon the instantaneous wire position. Some of the scattered light from each was collected and focussed on a photodiode. Since the vertical and stream-wise wire displacements were measured at opposite ends of the wire, and since there were laser radiation intensity gradients along the direction of wire displacement,

- The dimensionless frequency is defined as $f . l / U$ where $f$ is frequency $(\mathrm{Hz}), l$ is a length $(\mathrm{m})$ and $U$ is the mean forward speed of the insect $\left(\mathrm{m} \mathrm{s}^{-1}\right)$.

$\dagger$ The Reynolds number is defined as $U . l / \nu$, where $\nu$ is the kinematic viscosity. 
It seems safe to assume that the 'cross-talk' between the displacement component signals was minimized. The (analogue) wire displacement signals were digitized, and stored on a PDP II/40 computer. They were later interpreted in terms of forces by a calibration procedure: an electromagnetic technique was used to apply known static and dynamic forces to the wire. This required that a copper wire be used as the taut string, and the following relation,

$$
\mathbf{F}=i \int \mathbf{B} x d \mathbf{l}
$$

was applied. B was the magnetic field which surrounds the mid-section of the wire during calibration, $i$ the wire current, and $d \mathbf{l}$ an element of length in the wire direction. This permitted application of a known force to the wire by setting the current. To evaluate the response of the wire both statistically and dynamically, both direct and alternating current were used.

In practice, a known force was applied to the wire to match the displacement waveform generated by the insect flying into the airstream. The periodic, insectgenerated waveform can be characterized by its frequency, phase, and amplitude content. The blowfly remained attached to the wire during the calibration, so the dynamical system remained unchanged.

Several typical wire response curves for pure vertical and horizontal force inputs were obtained (Buckholz, 1978). Since the response curves were frequency-dependent the cross-talk was also frequency-dependent. However, data accumulated during the calibration indicated that cross-talk was not a problem. When streamwise displacement signals for both vertical forces and stream-wise forces on the wire were recorded; the ratio of the signal amplitude for a vertical force to that for a stream-wise force, both at $\mathrm{x} 5 \mathrm{OHz}$, was 0.025 . Subsequent verification at other wing-beating frequencies and higher harmonics show similar results. The wire was indeed found to behave as a lightly damped linear oscillator, including $180^{\circ}$ phase shifts occurring across eigenfrequencies. The presence of the eigenfrequency spectral peaks was not a problem because the system could be 'tuned' to move the eigenfrequencies away from the wing beating frequency and its harmonics.

The drag on the wire as a function of Reynolds number (based on wire diameter) was found to be within I dyn of the similar data given by Tritton (1959): I dyn is roughly $2 \%$ of the nominal blowfly weight.

Given the size of available computer memory and the region of spectral interest (i.e. $100-500 \mathrm{~Hz}$ ), the wing beating frequency and its higher harmonics were discerned to $\pm 0.5 \mathrm{~Hz}$, using digital Fourier transforms of the streamwise and vertical wire displacement signals.

\section{EXPERIMENTAL MATERIALS AND APPROACH}

The blowfly was used as the experimental animal because of its availability, large size, ease of attachment and previous kinematic studies (Nachtigall, 1966). Pupae were purchased from the Carolina Biological Supply Company and the adults reared on dry sugar, liver slices, and water.

An open, manually variable speed, wind tunnel with a $4 \times 3$ in jet and are con- 
traction ratio of 17 : I was used to generate a smooth, uniform air flow. Air speed was measured with a pitot-static tube using a Datametric Barocel Electronic Manometer. The difference between total and static pressure was measured and the speeds calculated using the steady Bernoulli equation.

The insect was lightly etherized and then bound to a $3 \mathrm{~mm}$ wire ring by a small dash of warm wax. The wing was then attached to the midpoint of the wire. Wing trajectory and wire position were kept separated by the ring, which acts as a spacer. The insect was anaesthetized during the attachment procedure by a puff of ether. The ether effects were observed to last a maximum of $30 \mathrm{~min}$. A foot support was provided until the etherization effects were gone, and 'flight' was initiated by the air movement and removal of the foot support. The mounting technique did not fix the insect body angle relative to the oncoming flow; the only constraint on wire rotation was that imposed by the fixed end-points. Thus, the angle of attack was effectively selected by the insect, within the mechanical constraints imposed by the wire.

\section{THE MEASUREMENTS}

Nachtigall's ( 1966 ) wind tunnel was controlled by the unbalanced horizontal force experienced by the fly. This elegant procedure was not feasible in this experiment. An alternative possibility would have been to measure the mean force components and adjust the wind-tunnel speed so as to balance the mean horizontal force. This would have set the airstream at the preferred flying speed. Unfortunately our method was not that direct, since mean forces were known only after a calibration of the raw wire displacement data. In this series of experiments, the wind speeds used were over the range $2 \cdot 3-3.5 \mathrm{~m} \mathrm{~s}^{-1}$. We chose a range of wind speed to assure ourselves that we covered the preferred flying speed. This allowed some observation of performance at speeds close to, but not necessarily at, the preferred flight speed. Wind speeds were measured in the 'potential core' of the exit jet, in a plane perpendicular to the flow.

The mounting ring* was an additional source of drag. This increase was not measured directly, but was expected to be small compared to the drag of the supporting wire. At a rough approximation, we consider the ring as two circular cylinders placed one behind the other. The drag of the second cylinder is considerably less than that on the first (Horner, 1965). The drag of the ring was estimated to be less than I dyn by forming the Reynolds number on the minor diameter and on the speed range of $\mathrm{I}-4 \mathrm{~m} \mathrm{~s}^{-1}$ and using the results for a circular cylinder in a uniform flow (Tritton, 1959).

Lift and drag fluctuation amplitudes and spectra appear in Table I, for eight different blowflies. These results were obtained from data records nominally $\mathrm{I} s$ in length containing 1024 points. Data records of shorter length showed no harmonic content higher than the third harmonic of the wing beating frequency.

As mentioned earlier, the body angle was not controlled as an independent variable; thus the body angle during the flight tests was set by the insect. The body angle was visually observed to be close to $\circ \pm 5^{\circ}$ for the results given in Table 1 .

The wire Reynolds number based on diameter for the speed range of I to $3.3 \mathrm{~m} \mathrm{~s}^{-1}$

- The major diameter wa $3 \mathrm{~mm}$ and the minor one $0.5 \mathrm{~mm}$. 


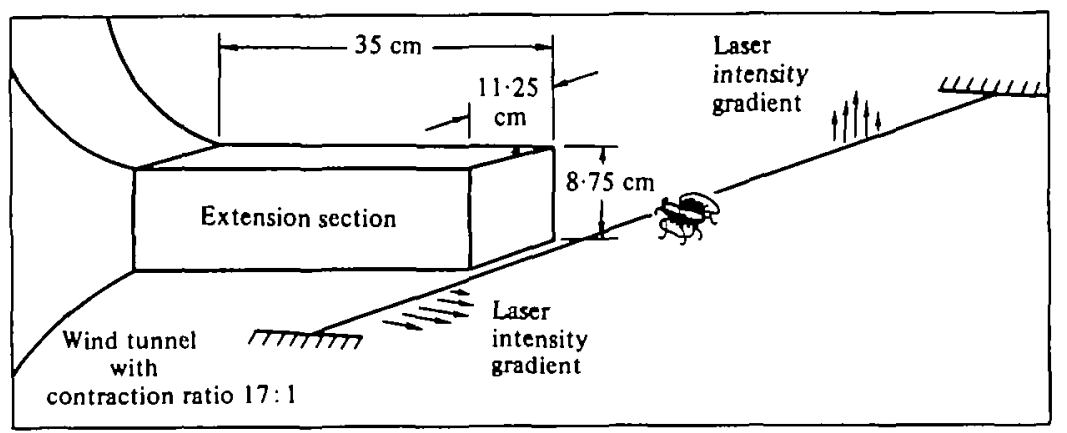

Fig. I. Schematic diagram of the jet and taut string. The insect is mounted on the wire midpoint, which is positioned at the centre of the rectangular jet. The insect is mounted approximately $75 \mathrm{~mm}$ from the exit plane of the extension section (length scales are not mutually consistent.

Table I. Spectral decomposition of the amplitude for lift and drag of eight different blowflies flying fixed in a wind tunnel

(Here the force amplitudes correspond to the coefficients $l_{1}, l_{2}$ and $l_{2}$ and $d_{1}, d_{2}$ and $d_{2}$ given in equations (2) and (3).)

\begin{tabular}{|c|c|c|c|c|c|c|c|c|c|c|}
\hline \multirow{3}{*}{$\begin{array}{c}\text { Insect } \\
\text { no. }\end{array}$} & \multicolumn{3}{|c|}{ Beating frequency } & \multicolumn{3}{|c|}{ Second harmonic } & \multicolumn{3}{|c|}{ Third harmonic } & \multirow{3}{*}{$\begin{array}{l}\text { Speed } \\
(\mathrm{cm} / \mathrm{sec})\end{array}$} \\
\hline & \multirow[b]{2}{*}{$\mathrm{Hz}_{2}$} & \multicolumn{2}{|c|}{ Force (dyn) } & \multirow[b]{2}{*}{$\mathrm{Hz}$} & \multicolumn{2}{|c|}{ Force (dyn) } & \multirow[b]{2}{*}{$\mathrm{Hz}$} & \multicolumn{2}{|c|}{ Force (dyn) } & \\
\hline & & Lift & Drag & & Lift & Drag & & Lift & Drag & \\
\hline I & 145 & $52 \cdot 0$ & 145 & 290 & 5.5 & $1 \cdot 0$ & 435 & 0.0 & $3 \cdot 4$ & 300 \\
\hline 2 & 145 & 65.0 & 50.0 & 290 & $3 . \mathrm{C}$ & $4 \cdot 6$ & 435 & 0.0 & 0.0 & 340 \\
\hline 3 & 130 & $52 \cdot 0$ & 3.8 & 260 & $3 \cdot 2$ & $1 \cdot 4$ & 390 & 3.9 & 0.6 & 318 \\
\hline 4 & 150 & 22.0 & 240 & 300 & 0.0 & 8.6 & 450 & 0.0 & 0.1 & 325 \\
\hline 5 & 120 & 15.0 & $4 \cdot I$ & 240 & 4.5 & 0.3 & 360 & 0.0 & 0.0 & 235 \\
\hline 6 & $15 \mathrm{I}$ & 14.0 & $9 \cdot 2$ & 302 & 0.5 & 40 & 453 & 0.0 & 0.0 & 250 \\
\hline 7 & 125 & 19.8 & 18.0 & 250 & $1 \cdot 2$ & 5.0 & 375 & 0.0 & 0.0 & 320 \\
\hline 8 & 141 & 19.6 & 7.7 & 282 & 2.4 & $2 \cdot 3$ & 423 & 0.0 & 0.0 & 325 \\
\hline
\end{tabular}

is 6-20, well below the critical Reynolds number for appearance of the KármánBénard vortex street. The nominal Reynolds number for the blowfly is 600 based on a chord length of $8 \mathrm{~mm}$ and a flight speed of $2.5 \mathrm{~m} \mathrm{~s}^{-1}$ and the reduced frequency is 0.5 based on a wing-beating frequency of $140 \mathrm{~Hz}$ and a wing length of $10 \mathrm{~mm}$.

The calibration method made it possible to correct for the phase shift between force and displacement introduced by the mechanical system; the time course of the force exerted by the thorax on the wire could thus be determined. The discrete spectral nature of the displacement signal allowed a simple correction at each frequency found in the wire displacement signals. To compare the results for different insects, the fundamental frequency component of the lift signal was taken as having zero phase angle. The periodic lift and drag experienced by the insect thorax were fitted by least-squares to the following expressions:

and

$$
l(t)=l_{1} \cos \omega_{0} t+l_{2} \cos \left(2 \omega_{0} t+\phi_{2}\right)+l_{3} \cos \left(3 \omega_{0} t+\phi_{3}\right)
$$

$$
d(t)=d_{1} \cos \left(\omega_{0} t+\psi_{1}\right)+d_{2} \cos \left(2 \omega_{0} t+\psi_{2}\right)+d_{3} \cos \left(3 \omega_{0} t+\psi_{3}\right)
$$



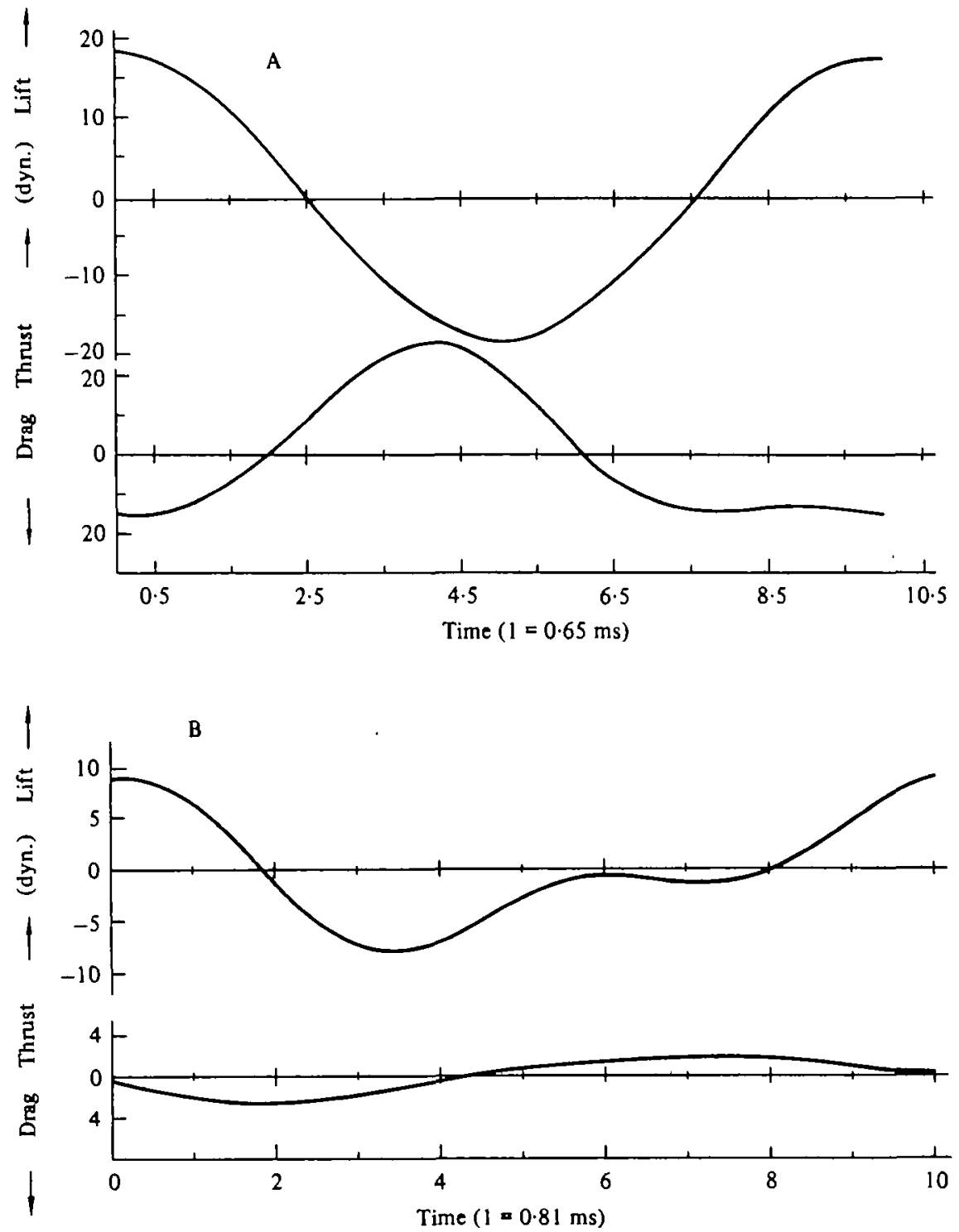

Fig. 2. (A, B) Lift and drag for one period of the wing beating frequency for two different flies not lifting their own weight.

Several insects were successfully experimented upon and the amplitude, frequency, and phase angle content for four of them are reported in Table 2 and in Figs. $2 \mathrm{~A}$ to $3 \mathrm{~B}$.

The functions shown in Figs. $2 \mathrm{~A}$ to $3 \mathrm{~B}$ correspond to the constants given in Table 2 for equations (2) and (3). Each insect performance was judged successful if the waveform generated by the insect-induced wire displacement was periodic and remained so over the I min requiring to take ten I 8 data records. Any grasping motions of the legs were easily observed to cause departures from the periodicity i 

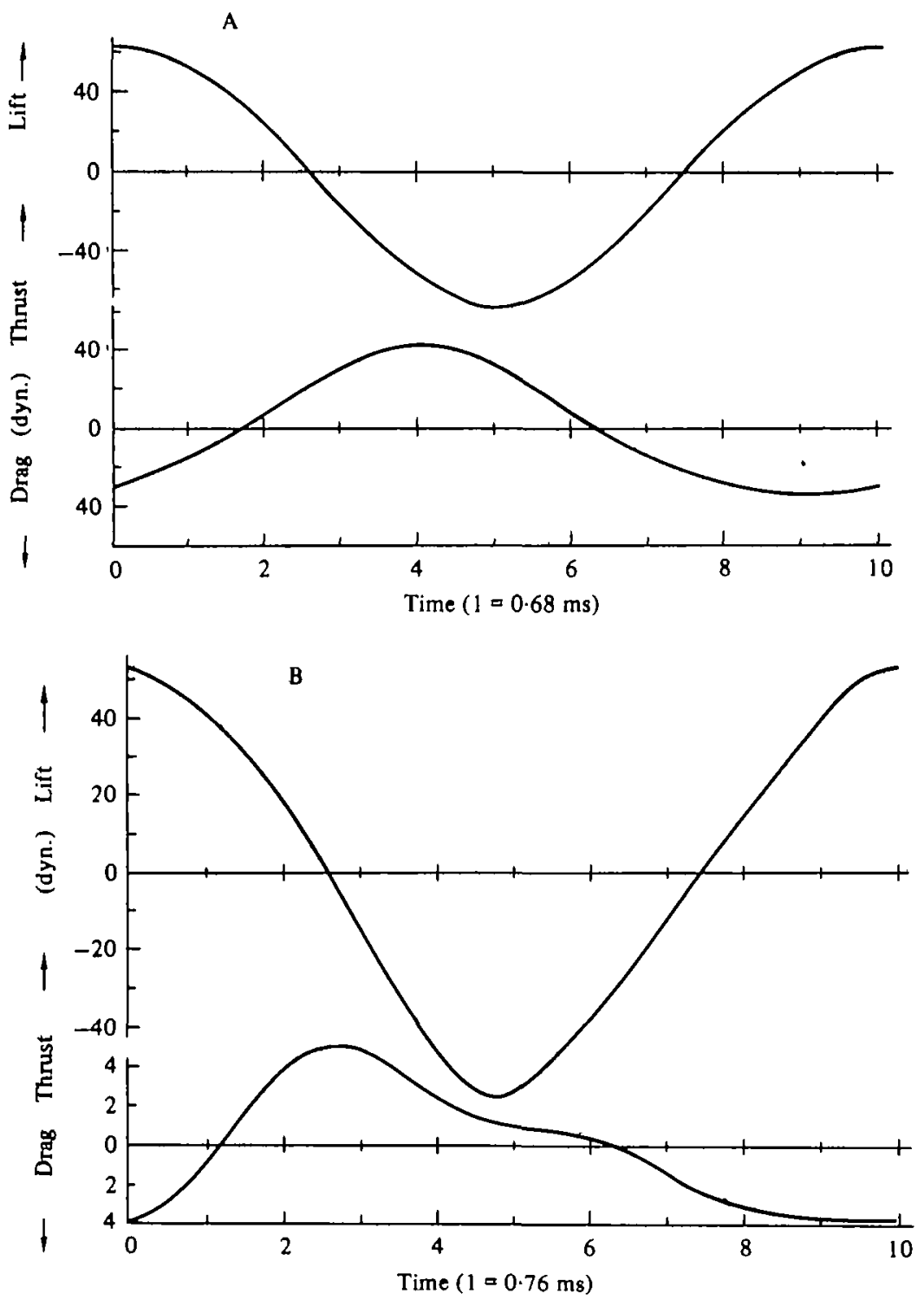

Fig. 3. (A, B) Lift and drag over one period of the wing beating frequency for two different flies lifting additional weight. The forces are a combination of the aerodynamic and wing inertia effects. Spectral data for the waveforms are given in Table 2. Each curve is constructed by a Fourier series least-squares fit to I $\mathrm{B}$ of calibrated wire displacement data. The mean streamwise and vertical forces have been subtracted out.

the displacement waveform. Data recorded during such events were discarded. The visually determined body flight angle for these four tests was again $\circ \pm 5^{\circ}$. The mean vertical forces recorded for the flight data given in Figs. $2 \mathrm{~A}$ to ${ }_{3} \mathrm{~B}$ were $47,36,105$ and 63 dyn respectively. As the nominal weight of the blowfly was 50 dyn the results shown in Fig. 2A and B are for blowflies not lifting their own weight. The force taveforms shown in Fig. $3 \mathrm{~A}$ and $\mathrm{B}$ are for blowflies lifting additional weight. 
Table 2. Force amplitudes and phase angles for Figs. $2 A$ to $3 B$

(These results correspond to the truncated Fourier series for $l(t)$ and $d(t)$ given by equations $(2)$ and (3), and $\beta$ is the reduced frequency.)

\begin{tabular}{|c|c|c|c|c|c|c|c|c|}
\hline Figure & $\begin{array}{l}\text { Frequency } \\
(\mathrm{Hz})\end{array}$ & $\begin{array}{l}\text { Wind speed } \\
(\mathrm{cm} / \mathrm{s})\end{array}$ & $l_{1}$ & $l_{1}$ & $l_{3}$ & $\phi_{2}$ & $\phi_{2}$ & $\beta$ \\
\hline 2 & & & $\begin{array}{l}\text { Lift } \\
\text { I } 8 \cdot 0\end{array}$ & 0 & 0 & $0^{\circ}$ & $0^{\circ}$ & 0.47 \\
\hline 3 & $\begin{array}{l}155 \\
148\end{array}$ & $\begin{array}{l}325 \\
345\end{array}$ & 67.0 & 3.4 & 0 & $182^{\circ}$ & $0^{\circ}$ & 0.428 \\
\hline 4 & $13 I$ & 310 & $52 \cdot 0$ & $3 \cdot 0$ & 0 & $236^{\circ}$ & $0^{\circ}$ & 0.422 \\
\hline 5 & 124 & 235 & $6 \cdot I$ & 3.7 & 0 & $110^{\circ}$ & $0^{\circ}$ & 0.527 \\
\hline 2 & 155 & 325 & $\begin{array}{l}\text { Dras } \\
21 \cdot 8\end{array}$ & 7.5 & 0.2 & $213^{\circ}$ & $68^{\circ}$ & $337^{\circ}$ \\
\hline 3 & 148 & 345 & $39 \cdot 0$ & $5 \circ$ & 0 & $215^{\circ}$ & $73^{\circ}$ & $0^{\circ}$ \\
\hline 4 & 131 & 310 & 3.9 & $1 \cdot 4$ & 0.7 & $233^{\circ}$ & $186^{\circ}$ & $94^{\circ}$ \\
\hline 5 & 124 & 235 & $-2 \cdot I$ & -0.4 & $\circ$ & $89^{\circ}$ & $205^{\circ}$ & $0^{\circ}$ \\
\hline
\end{tabular}

Table 3. The kinematic-dynamic phase angle for one blowfly flying fixed in a wind tunnel (The wind speeds were in the range $\left(2 \cdot 5^{-2} \cdot 7 \mathrm{~m} \mathrm{~s}^{-1}\right.$.)

\begin{tabular}{|c|c|c|c|c|c|c|c|c|}
\hline $\begin{array}{c}\text { Insect } \\
\text { no. }\end{array}$ & $\begin{array}{c}\text { Frequency } \\
(\mathrm{Hz})\end{array}$ & $\begin{array}{l}\text { Phase } \\
\text { (deg) }\end{array}$ & $\begin{array}{c}\text { Insect } \\
\text { no. }\end{array}$ & $\begin{array}{l}\text { Frequency } \\
(\mathbf{H z})\end{array}$ & $\begin{array}{l}\text { Phase } \\
\text { (deg) }\end{array}$ & $\begin{array}{c}\text { Insect } \\
\text { no. }\end{array}$ & $\begin{array}{c}\text { Frequency } \\
(\mathrm{Hz})\end{array}$ & $\begin{array}{l}\text { Phase } \\
\text { (deg) }\end{array}$ \\
\hline I & 144.5 & 100 & I I & $139^{\circ} 0$ & 125 & $2 \mathrm{I}$ & 135.3 & 132 \\
\hline 2 & 143.4 & 100 & 12 & $139^{\circ} 0$ & 125 & 22 & $13 \times 9$ & 130 \\
\hline 3 & 143.7 & 107 & I 3 & I $39^{\prime} \mathrm{I}$ & 128 & 23 & 131.9 & 132 \\
\hline 4 & 144.2 & 102 & 14 & $137^{\circ} \mathrm{I}$ & I 2 I & 24 & 132.9 & I 37 \\
\hline 5 & 143.3 & 103 & I 5 & 139.5 & 125 & 25 & $13 I^{\prime} 4$ & 133 \\
\hline 6 & $143^{\circ} 0$ & 87 & 16 & $139^{\circ} \mathrm{I}$ & 127 & 26 & $131 \cdot 3$ & I 34 \\
\hline 7 & 142.4 & 9I & 17 & 139.4 & 129 & 27 & 133.5 & 132 \\
\hline 8 & $141^{10}$ & 95 & 18 & I 37.9 & I 26 & 28 & $132 \cdot 1$ & I 33 \\
\hline 9 & 143.4 & 101 & 19 & 138.5 & I 26 & & & \\
\hline 10 & $142 \cdot 3$ & 96 & 20 & 138.5 & 126 & & & \\
\hline
\end{tabular}

In contrast to Nachtigall's balancing of the mean streamwise force, we have mean streamwise forces due to the blowfly and the wire-ring support. For Figs. $2 \mathrm{~A}$ to $3 \mathrm{~B}$ the mean streamwise force was $18,36,54$ and 25 dyn respectively; the unbalanced mean streamwise force on the blowfly was $3,27,40$ and 7 dyn respectively. However, the force waveforms shown in Figs. 2A, $3 \mathrm{~A}$ and $\mathrm{B}$ are similar although the mean force components for each figure are different. Moreover, we see from Table 2 that the reduced frequencies (based on span) for Figs. $2 \mathrm{~A}, 3 \mathrm{~A}$ and $\mathrm{B}$ are similar.

An objective of insect aerodynamics flight research is to establish a detailed, instantaneous connexion between the wing-motion kinematics and the simultaneous wing forces. Nachtigall (1966) has presented detailed wing-motion data from highspeed motion pictures. In the present investigation it was not feasible to take motion pictures simultaneously with the dynamic-force balance records. As a first step in rectifying this omission the phase angle between the maximum vertical position of the wing tip and the maximum thrust was measured. Once again an optical technique was employed; a laser beam was positioned in the path of the wing so that the beam was intercepted by the wing tip when it reached its maximum vertical position. The streamwise wire displacement was simultaneously measured for comparison with th 


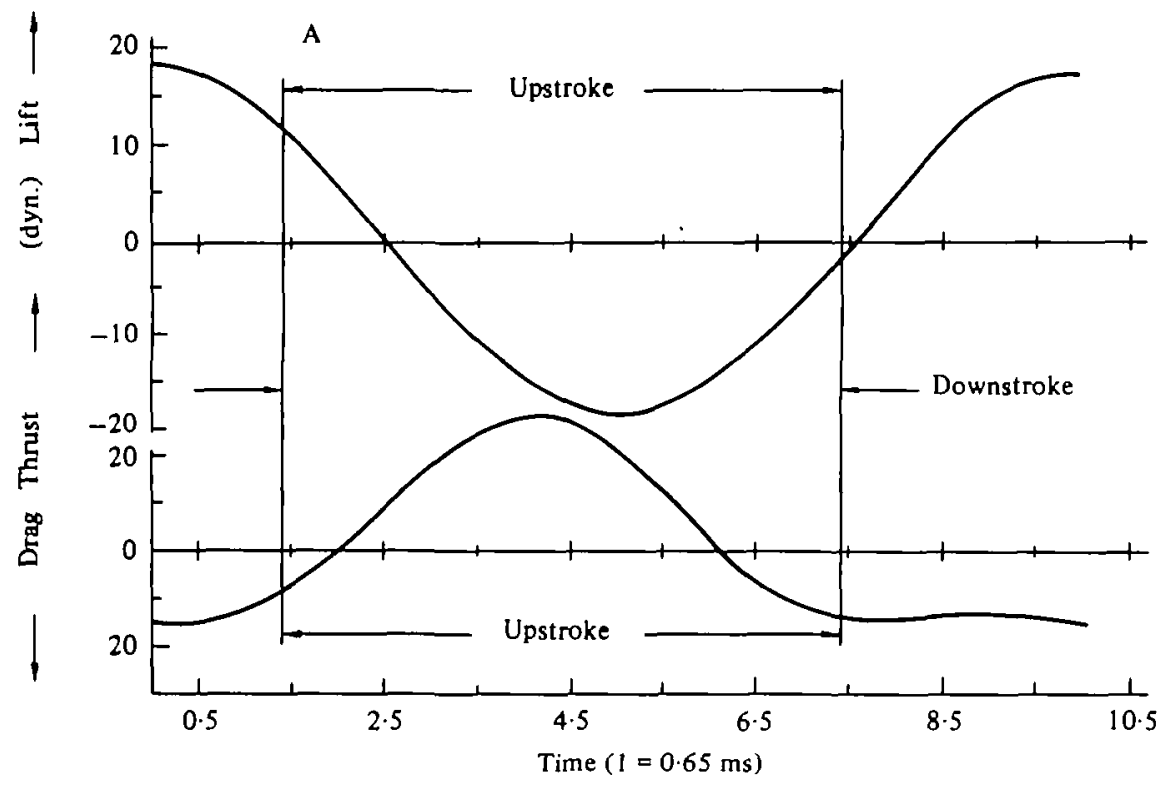

B

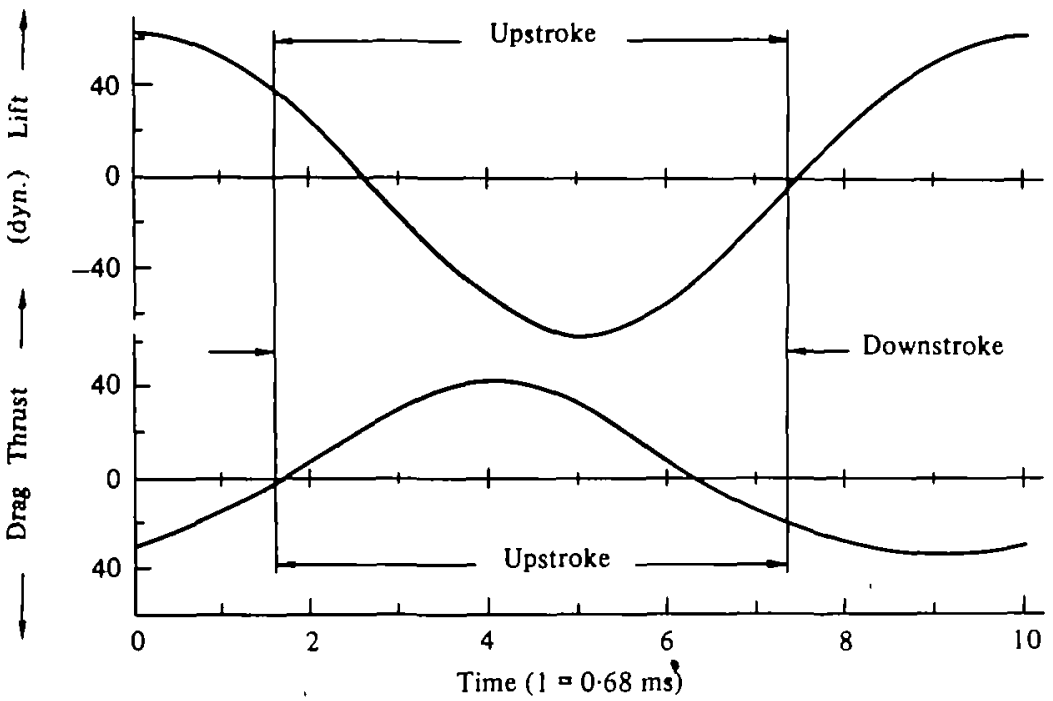

Fig. 4. (A, B) The instantaneous lift and drag waveforms from Fig. $2 \mathrm{~A}$ and $3 \mathrm{~A}$ are combined with the measured kinematic-dynamic phase angles shown in Table 3. The upstroke and downstroke regions are shown using a $0.6-0.4$ division of the wing beating period (Nachtigall, 1974). This result is obtained from the composition of results from two different insects.

square-wave generated by the broken laser beam. The phase lead of the maximum thrust is shown in Table 3 .

These data were obtained from one insect flying in the speed range 2.7 to $2.5 \mathrm{~m} \mathrm{~s}^{-1}$. The phase angle was found to increase slightly as the speed decreased. Using a ypical' phase angle of $11^{\circ}$ (Table 3) and the waveforms in Figs. $2 \mathrm{~A}$ and $3 \mathrm{~A}$, 
Fig. $4 \mathrm{~A}$ and $\mathrm{B}$ indicate where the downstroke and upstroke regions occur based on a $60 \%$ to $40 \%$ division respectively. In this experimental set-up the technique for measuring the vertical wing-tip position and the streamwise force did not allow the simultaneous measurement of the time course of the vertical force. Fig. $4 \mathrm{~A}$ and $\mathrm{B}$ are thus composites of results from two different insects.

There were some changes in wing beating frequency during recording. Changes of up to $10 \%$ occurred during some of the phase-angle measurements. In the case of one particular blowfly the phase was observed to decrease with decreasing frequency; in this case the magnitude of the force generated was considerably smaller than that shown in Figs. $2 \mathrm{~A}$ to $3 \mathrm{~B}$.

\section{DISCUSSION}

A question common to all tethered insect flights is their relation to free flight. Although no completely satisfactory solution to this problem has yet been given, the experimental evidence (Vogel, 1966) indicated that flight performance between the two cases are not greatly different. This is assumed with the present results, since our mounting is similar to Vogel's. It is significant that Nachtigall (Ig66), using an abdominal mounting, and Wood (1970), using (as in this investigation) a thoracic mounting, obtained different kinematical results. The dynamical implications of these differing wing motions are not fully understood.

The forces measured in this investigation is a combination of two effects: the aerodynamic force, experienced by the wing and body, and the wing inertial force. It follows that the fluid dynamical forces experienced by the thorax can be isolated by separation of the wing inertial forces. Simultaneous recording of wing-beating kinematics during this experiment was precluded because of the high light intensity needed for high-speed movies. The kinematical observations of Nachtigall (1966) are thus necessary for guidance when such results are needed.

The absence of significantly higher harmonic content in lift and drag components of force is rather surprising in view of the complex dynamical and fluid mechanical mechanisms which might be involved. This absence is unexpected in the light of the flight data showing wing-beating kinematics for the fly Phormia regina (Nachtigall, 1966). in which the wing trajectories have significant amplitude content associated with higher harmonics of the wing beating frequency. Both the geometrical angle of attack for the outer one-third span and the wing-tip trajectory contain these higher harmonics. Of course, each of these is a source of higher harmonics in the forces. An additional mechanism which might be expected to introduce higher harmonics arises through the small-amplitude two-dimensional wing theories: leading-edge 'suction' forces contain terms proportional to twice the kinematic input frequency. Although such theories are for small-amplitude motions the mechanism is of qualitative interest. Despite these mechanisms, the wing-beating fundamental frequency was the dominant mode in the lift and drag forces with the drag signal showing slightly more harmonic distortion among the insects tested.

The wind speeds used in this investigation were in the neighbourhood of the reported flying speeds (Nachtigall, I966; Wood, 1970). Furthermore, the phase angle and amplitude measurements showed no particular trend with wind speed. 
Previous studies of wing movement show that most lift occurs during the downstroke and most thrust during the upstroke (Nachtigall, 1966). However, at the extreme vertical positions the Phormia regina wing movement was too complicated for any standard aerodynamic analysis. The hot-wire measurements of Wood (1970) in the wake of the Calliphora erythrocephala were interpreted as being consistent with Nachtigall's (1966) conclusions. The present measurements are also consistent with these conclusions since the maximum lift occurred during the downstroke and maximum thrust during the upstroke.

Some of the results obtained for the wind-speed region near $2.5 \mathrm{~m} \mathrm{~s}^{-1}$ indicate that more second harmonic content was present in the lift when compared to the lift generated at higher wind speeds near $3.0 \mathrm{~m} \mathrm{~s}^{-1}$. Fig. $2 \mathrm{~B}$ shows a corresponding lower second harmonic content for the drag when the result is compared to the higher wind-speed results. It has been suggested by Nachtigall (1966), based on high-speed cinematography, that two peaks can occur in the lift with the larger occurring during the downstrokes. In addition, the hot-wire measured-velocity field in the wake of the Calliphora erythrocephala (Wood, 1970) show that two peaks in the vertical velocity field can occur. The result given in Fig. 2 B is consistent with Nachtigall's (1966) hypotheses concerning the appearance of the two peaks.

I would like to thank Professor S. Corrsin, who jointly conceived the system and reviewed this manuscript. This work was supported by the National Science Foundation, Engineering Mechanics and Biophysical Fluid Mechanics Programs.

\section{REFERENCES}

Bucкноцz, R. H. (1978). Some aspects of unsteady insect aerodynamics: Acceleration potential methods in plane unsteady airfoil theory, and measurements of unsteady-periodic forces generated by the blowfy. Ph.D. thesis, Johns Hopkins University.

Buckнolz, R. H. (I979). A two-component dynamic wind tunnel balance for mounted insects. (Submitted to the $\mathcal{F}$. Phys. E.)

Horner, S. F. (1965). Fluid-Dynamic Drag. Published by the Author.

Jensen, M. (1956). Biology and physics of locust. III. The aerodynamics of locust flight. Phil. Trans. R. Soc. 239, 5 I $1-512$.

Nachtigall, W. (i 966). Die Kinematick der Schalagflugelbewungen von Dipteran : methodische und analytisch Grundlagen zur Biophysik des Insectenflugs. $Z$, vergl. Physiol. 52, $155^{-2}$ I 1.

Nachtigall, W. (I 974). Insects In Flight. New York: McGraw-Hill.

RaINey, R. C. (1976). Insect Flight. Oxford: Blackwell Scientific Publications.

TritTon, D. J. (1959). The flow past a circular cylinder at low Reynolds numbers. Y. Fluid Mech. 6, $547-567$.

VOCEL, S. (I 966). Flight in drosophila. I. Flight performance of tethered flies. 7. exp. Biol. 44, 567-578.

WeIs-Fogh, T. (1956). Biology and physics of locust flight. II. Flight performance of the desert locust (Schistocerca gregaria). Phil. Trans. R. Soc. B 239, 459-1 5 Io.

WOOD, J. (1970). A study of the instantaneous air velocities in a plane behind the wings of certain diptera fying in a wind tunnel. $f$. exp. Biol. 52, 17-25.

Wu, T. Y., Brokaw, C. J. \& Brennen, C. (1975). Swimming and Flying in Nature vols. 1 and 2. New York: Plenum Press. 
